\section{$\underset{\text { hommes }}{\text { \& migrations }}$}

\section{Hommes \& migrations}

Revue française de référence sur les dynamiques

migratoires

$1310 \mid 2015$

Fashion Mix

\title{
Sylvain Prudhomme, Les Grands
}

L'Arbalète/Gallimard, 2014, 208 pages, 19,50€

\section{Mustapha Harzoune}

\section{(2) OpenEdition}

\section{Journals}

\section{Édition électronique}

URL : http://journals.openedition.org/hommesmigrations/3211

DOI : 10.4000/hommesmigrations.3211

ISSN : 2262-3353

\section{Éditeur}

Musée national de l'histoire de l'immigration

\section{Édition imprimée}

Date de publication : 1 avril 2015

Pagination : 194-195

ISBN : 978-2-919040-31-5

ISSN : $1142-852 X$

\section{Référence électronique}

Mustapha Harzoune, «Sylvain Prudhomme, Les Grands », Hommes \& migrations [En ligne], 1310 | 2015, mis en ligne le 17 décembre 2015, consulté le 24 septembre 2020. URL : http://

journals.openedition.org/hommesmigrations/3211; DOI : https://doi.org/10.4000/ hommesmigrations.3211 


\section{LIVRES}

convolèrent, allègrement d'une seule voix, à cette vaine politique de contrôle de l'immigration. Ne pas oublier ce que le pays - les immigrés surtout ! - doit à Poniatowski et à sa circulaire sur le titre de séjour qui "du jour au lendemain" inventa "une nouvelle race de citoyens: les sans-papiers". Et cette prophétie d'un Malien visionnaire : "Un jour, un fils d'immigrés sera président de ce pays et je suis sûr que c'est lui qui chassera tous les étrangers."

Alors que le maelström centrifuge éjecte l'immigré hors du cercle des humains, Gauz le réintègre : I'Africain peut aussi voyager pour le kif. Pour découvrir le monde et non pour fuir misère et dictature: "Ossiri lui révéla combien il était riche du simple fait d'avoir voyagé. 'Kassoum, juste parce que tu es là, tu es un homme meilleur. Meilleur que les gens du Colosse parce qu'ils ne connaitront jamais Paris. Meil- leur que les gens de Paris parce qu'ils ne connaitront jamais le Colosse.'” II faut évoquer enfin Angela, ci-devant expatriée, retournée au pays où ses tenues lui valent le sobriquet peu amène de "Blanche". Femme de caractère et de principes, elle dispense des leçons sur l'aliénation vestimentaire (ah ! le wax hollandais) ou "nutritive" (le pain engrosse les paysans du Nord et appauvrit le paysan africain): "Comprenez bien les enfants, on ne peut pas être indépendants quand même ce qu'on mange vient de ceux qui nous aliènent. Une grande partie de la richesse nationale retourne en Occident par l'achat de tonnes de blé dont nous avons besoin pour satisfaire les caprices du pain."

Le ton est léger, badin, mais, sans en avoir l'air, Gauz revisite l'ordre économique et politique mondial, l'histoire de nos représentations, et des décennies de politique migratoire. $\mathrm{M}$. $\mathrm{H}$.

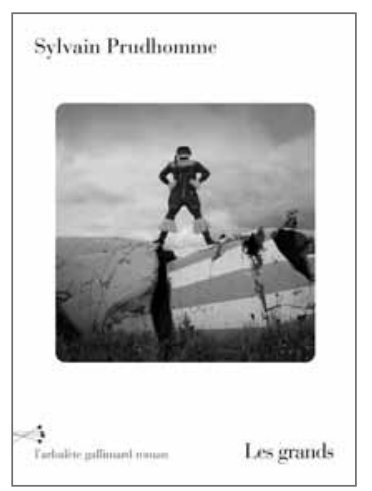

l'histoire de l'immigration qui couronne un roman dont le ou les thèmes offrent quelques variations sur l'exil et/ou cette tectonique des peuples, cette "branloire

\section{Sylvain}

\section{Prudhomme} Les Grands

L'Arbalète/Gallimard, 2014, 208 pages, 19,50 euros.

Voici donc le lauréat 2015 du Prix littéraire de la Porte Dorée, prix du Musée national de

.

\section{famili} algérienne, portugaise, italienne. Les
Grands racontent la merveilleuse his-

pérenne" du monde, qui brasse et parfois entrechoque les hommes et les femmes de tous les continents. Sylvain Prudhomme y ajoute la rencontre par le décentrement, l'ouverture de la littérature hexagonale au monde par l'irruption de l'ailleurs, un universalisme partagé où la légitimité de l'Autre ne barbote pas sur les rives de la Seine ou du Tage, un peu d'exil aussi, celui de l'auteur en vadrouille sur le continent africain, celui qu'il porte par une histoire 
toire d'un groupe de musique - le Super Mama Djambo - qui, dans les années 1970, portait dans un créole savoureux, mélange de portugais et de langues du cru, les espoirs - et les premières désillusions - de l'indépendance version Guinée-Bissau. Le récit tient en une journée : elle s'ouvre sur l'annonce de la mort de Dulce, l'ex-chanteuse emblématique du groupe, et se termine par un concert hommage que les rescapés du Super Mama Djambo organisent le soir même. Cette journée forme un long travelling, une odyssée dans Bissau où se mêlent l'histoire et le présent de la ville, où se croisent quelques fantômes et des êtres bien vivants et qui ne demandent qu'à vivre. Ici, l'Afrique n'est ni fantasmée ni idéalisée, exit le misérabilisme et les larmes de crocodile ou les plats réchauffés du colonialisme à la papa. Avec Couto, le vieux guitariste du groupe, le lecteur déambule de quartier en quartier, dans une ville populaire et bigarrée. Couto et Dulce sont des personnages de fiction. Ces deux-là s'aimaient au temps de la gloire. La gloire a passé. Il faut croire que l'amour aussi. Du moins Dulce préféra assurer ses arrières avec Gomès, un héros de la lutte pour l'indépendance devenu l'homme fort du régime. Couto et Gomès ont deux rendez-vous. Le premier parce que Couto décide d'aller se recueillir devant le corps de Dulce. Le second sera pour plus tard, dans la nuit. La rue bissalienne bruit des préparatifs d'un coup d'État et l'annonce de ce concert pourrait contrarier les plans du chef d'étatmajor. Gomès lui-même.

Le lecteur découvre un pays, un peuple, des aspirations contrariées par les acca- pareurs d'indépendance. II entend les dialogues, par téléphone, entre ceux restés au pays et les autres, expatriés en Europe. Au temps des tournées mondiales du groupe, il s'amuse des saveurs comparées de l'Europe et de l'Afrique. L'Europe eldorado ? convoitée ? Pas forcément! Les organisateurs de festivals en France devraient offrir ce livre à bien des responsables consulaires, chiches et suspicieux dispensateurs de visas.

Pour écrire Les Grands ou le précédent, Là, avait dit Bahi, il faut aimer les gens. Et Sylvain les aime, à n'en pas douter. C'est peut-être pour cela que ses romans font du bien. Le Super Mama Djambo à Bissau, c'est un peu le Buena Vista Social Club à La Havane ou El Gusto à Alger : des êtres solaires, des pépères fragiles mais encore verts, des souvenirs à revendre et des rêves d'amour plein la tête. Encore et toujours. En chansons et en musiques. Exit ici la salsa ou le chaabi, l'ambiance chaleureuse, chaloupée, sensuelle, tendre est à la saudade. M. H. 